\title{
Direct synthesis of multilayer graphene on an insulator by Ni-induced layer exchange growth of amorphous carbon
}

H. Murata, K. Toko, N. Saitoh, N. Yoshizawa, and T. Suemasu

Citation: Appl. Phys. Lett. 110, 033108 (2017); doi: 10.1063/1.4974318

View online: http://dx.doi.org/10.1063/1.4974318

View Table of Contents: http://aip.scitation.org/toc/apl/110/3

Published by the American Institute of Physics

\section{Articles you may be interested in}

Observation of the Goos-Hänchen shift in graphene via weak measurements

Appl. Phys. Lett. 110, 031105031105 (2017); 10.1063/1.4974212

Electron radiation damage mechanisms in 2D MoSe2

Appl. Phys. Lett. 110, 033106033106 (2017); 10.1063/1.4973809

Antiferro-ferromagnetic transition in ultrathin $\mathrm{Ni}(\mathrm{OH}) 2$ layer grown on graphene surface and observation of interlayer exchange coupling in $\mathrm{Ni}(\mathrm{OH}) 2 /$ graphene/ $\mathrm{Ni}(\mathrm{OH}) 2$ nanostructures

Appl. Phys. Lett. 110, 032404032404 (2017); 10.1063/1.4974347

Tunneling field effect transistor integrated with black phosphorus-MoS2 junction and ion gel dielectric

Appl. Phys. Lett. 110, 033103033103 (2017); 10.1063/1.4974303

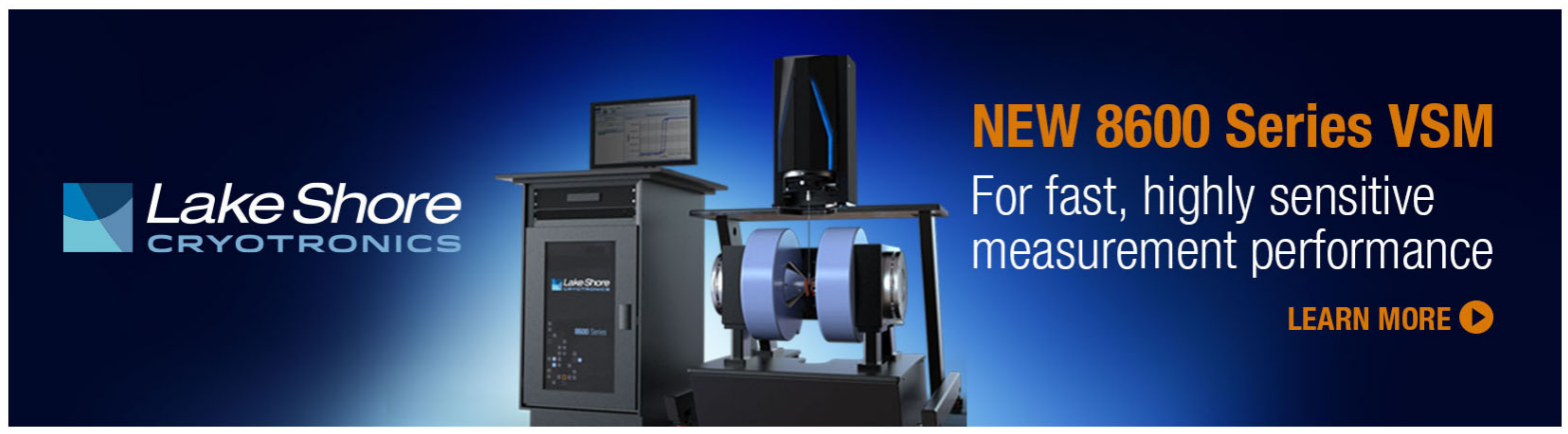




\title{
Direct synthesis of multilayer graphene on an insulator by Ni-induced layer exchange growth of amorphous carbon
}

\author{
H. Murata, ${ }^{1, a)}$ K. Toko, ${ }^{1, a), b)}$ N. Saitoh, ${ }^{2}$ N. Yoshizawa, ${ }^{2}$ and T. Suemasu ${ }^{1}$ \\ ${ }^{1}$ Institute of Applied Physics, University of Tsukuba, 1-1-1 Tennodai, Tsukuba, Ibaraki 305-8573, Japan \\ ${ }^{2}$ Electron Microscope Facility, TIA, AIST, 16-1 Onogawa, Tsukuba 305-8569, Japan
}

(Received 14 November 2016; accepted 6 January 2017; published online 19 January 2017)

\begin{abstract}
Multilayer graphene (MLG) growth on arbitrary substrates is desired for incorporating carbon wiring and heat spreaders into electronic devices. We investigated the metal-induced layer exchange growth of a sputtered amorphous $\mathrm{C}$ layer using $\mathrm{Ni}$ as a catalyst. A MLG layer uniformly formed on $\mathrm{a} \mathrm{SiO}_{2}$ substrate at $600{ }^{\circ} \mathrm{C}$ by layer exchange between the $\mathrm{C}$ and Ni layers. Raman spectroscopy and electron microscopy showed that the resulting MLG layer was highly oriented and contained relatively few defects. The present investigation will pave the way for advanced electronic devices integrated with carbon materials. Published by AIP Publishing.

[http://dx.doi.org/10.1063/1.4974318]
\end{abstract}

Multilayer graphene (MLG) has been actively investigated because of its high electrical/thermal conductivities and current-carrying capacity exceeding that of $\mathrm{Cu} .{ }^{1-3}$ MLG on arbitrary substrates opens the possibility of advanced electronic devices with low-resistance wiring and heat spreaders. Because graphene has a unique two-dimensional structure, its characteristics are anisotropic, and they deteriorate with the formation of grain boundaries. 4,5 Therefore, large-grained highly oriented MLG on insulators is highly desirable.

Mechanical transfer can be performed for graphene on arbitrary substrates. ${ }^{6}$ Because the transfer possibly damages graphene, a transfer-free process is essential for practical device applications. Low-temperature synthesis of graphene on insulators has been achieved using chemical-vapor deposition $^{7-11}$ and plasma-assisted vapor deposition ${ }^{12,13}$ with metal catalysts (e.g., $\mathrm{Cu}, \mathrm{Ni}, \mathrm{Fe}$, and $\mathrm{Co}$ ). These techniques are useful for directly forming a few-layer graphene on insulators, but they are not suitable for forming thick MLG, which is necessary for carrying a large amount of current or heat. In recent years, metal-induced solid-phase crystallization of amorphous carbon (a-C) or polymers has attracted increasing attention for the direct synthesis of MLG on insulators at relatively low temperatures $\left(<900{ }^{\circ} \mathrm{C}\right) .{ }^{14-25}$ Some of these techniques allow thick ( $>5 \mathrm{~nm})$ MLG to be formed by controlling the initial film thickness. ${ }^{19-26}$ However, further investigation is required to achieve a uniform highquality MLG on insulators.

In the field of group-IV semiconductors including $\mathrm{Si}^{27-31}$ $\mathrm{Ge}^{32-35}$ and SiGe, ${ }^{36,37}$ metal-induced layer exchange (MILE) allows large-grained $(>30 \mu \mathrm{m})$ highly oriented thin films to be formed on insulators. In MILE, an amorphous semiconductor layer crystallizes by "layer exchange" between the amorphous layer and a catalyst metal layer. ${ }^{31}$ Because the thickness of the crystallized layer is determined by that of the metal layer, it can be controlled by the deposition rate and

\footnotetext{
${ }^{\text {a) }} \mathrm{H}$. Murata and K. Toko contributed equally to this work.

b) Author to whom correspondence should be addressed. Electronic mail: toko@bk.tsukuba.ac.jp.
}

time of the metal layer. From the binary phase diagrams, we determined that $\mathrm{Ni}$ would work as a catalyst for layer exchange crystallization of a-C. In this study, we applied MILE to a-C to fabricate a high-quality MLG on an insulator at low temperatures.

The concept of this study is shown in Fig. 1. We aimed to perform a layer exchange between a-C and $\mathrm{Ni}$ layers. $\mathrm{Ni}$ and a-C thin films (each $50 \mathrm{~nm}$ thick) were sequentially prepared on quartz glass $\left(\mathrm{SiO}_{2}\right)$ using radio-frequency (RF) magnetron sputtering (base pressure: $3.0 \times 10^{-4} \mathrm{~Pa}$ ) with $\mathrm{Ar}$ plasma. The substrate temperature was $200^{\circ} \mathrm{C}$ for $\mathrm{Ni}$ and room temperature for a-C. The RF power was set to $50 \mathrm{~W}$ for $\mathrm{Ni}$ and $100 \mathrm{~W}$ for a-C. Samples were annealed at 600, 800, and $1000^{\circ} \mathrm{C}$ for $10 \mathrm{~min}$ in an Ar ambient to form MLG on the substrate by layer exchange. The Ni layers were then etched away by $\mathrm{FeCl}_{3}$ solution. For comparison, we also prepared an a-C layer directly on a $\mathrm{SiO}_{2}$ substrate without a $\mathrm{Ni}$ layer.

The quality of the $\mathrm{C}$ layers was evaluated by Raman spectroscopy (Nanophoton RAMANplus, spot diameter $5 \mu \mathrm{m}$ and wavelength $532 \mathrm{~nm}$ ). Because the substrate is transparent, a layer in contact with the substrate can be evaluated from the back side of the sample. Figure 2(a) shows that the sample before annealing has a large broad peak at around $1500 \mathrm{~cm}^{-1}$, corresponding to $\mathrm{a}-\mathrm{C},{ }^{20}$ only on the front side. These results confirm that an a-C layer is stacked on a $\mathrm{Ni}$ layer without mixing before annealing. Because the small peaks at around $1100 \mathrm{~cm}^{-1}$ originate from the $\mathrm{SiO}_{2}$ substrate, these peaks appear in all of the Raman spectra obtained from the back side of the samples.

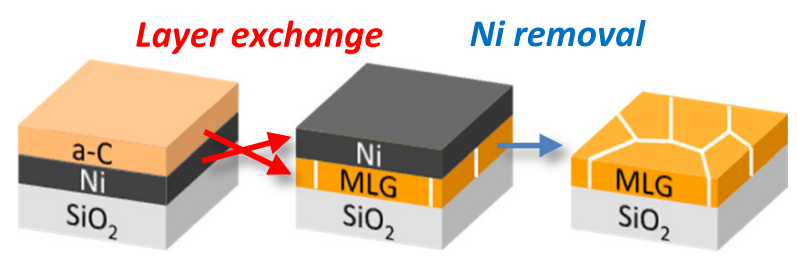

FIG. 1. Schematic diagram of the sample preparation procedure. 
The Raman spectrum of the front side of the sample annealed at $1000^{\circ} \mathrm{C}$ (Fig. 2(b)) has peaks at around 1350, 1580 , and $2700 \mathrm{~cm}^{-1}$, corresponding to the $\mathrm{D}$ (disordered mode), G (graphitic mode), and 2D (D mode overtone) peaks in the graphitic structure, respectively. ${ }^{19,20,24}$ In contrast, the Raman spectra of the front side of the samples annealed at 600 and $800^{\circ} \mathrm{C}$ have no peaks corresponding to C. It is worth noting that the a-C peaks present before annealing, as shown in Fig. 2(a), have disappeared for all of the samples. The Raman spectra of the back side of the samples (Fig. 2(c)) have sharp D, G, and 2D peaks corresponding to MLG. The Raman results suggest that the growth morphologies of the samples are as follows. When the growth temperature is low $\left(\leq 800^{\circ} \mathrm{C}\right)$, a MLG layer forms on the back side and a Ni layer forms on the front side. This means that a layer exchange between the $\mathrm{C}$ and Ni layers occurred. When the growth temperature is high $\left(>800^{\circ} \mathrm{C}\right)$, MLG forms on both the front and back sides. This is probably because the Ni layer deformed during annealing and resulted in a non-uniform layer exchange. The intensity ratio of the $\mathrm{G}$ to $\mathrm{D}$ peaks, corresponding to the crystal quality of MLG, ${ }^{10,14}$ is approximately 2.3 in the whole range of growth temperature (Fig. 2(c)). This value is smaller than that of some MLG synthesized at high
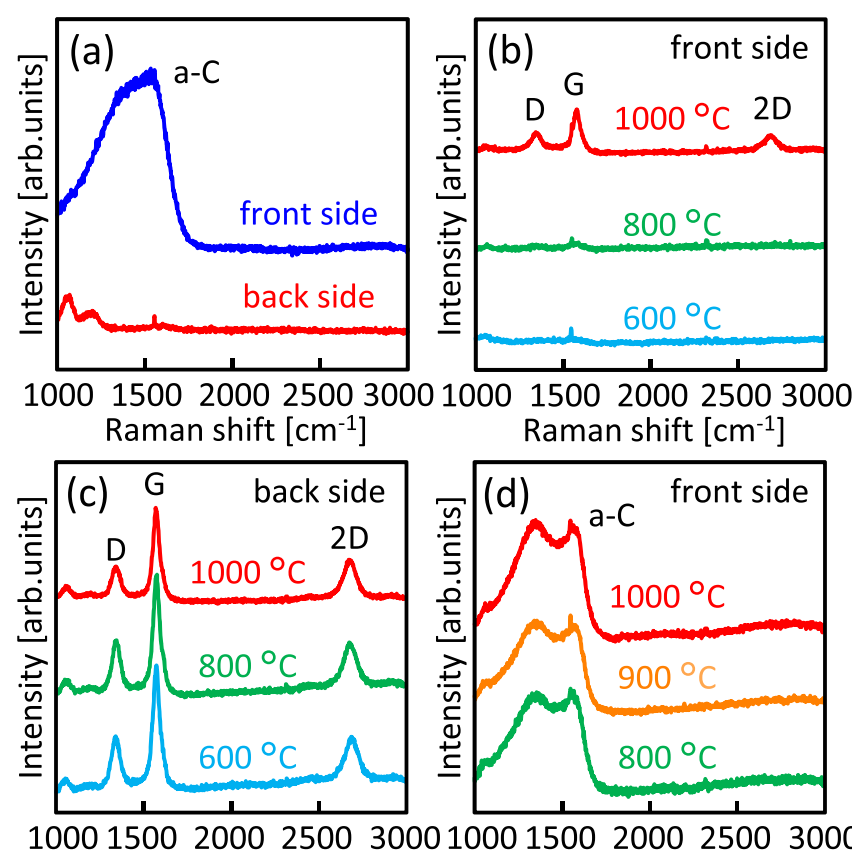

Raman shift $\left[\mathrm{cm}^{-1}\right]$

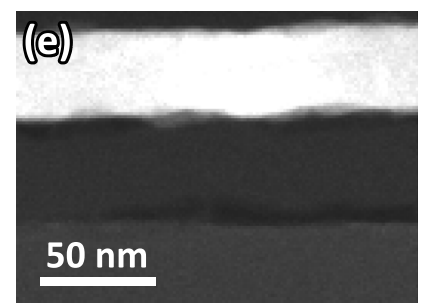

Raman shift $\left[\mathrm{cm}^{-1}\right]$

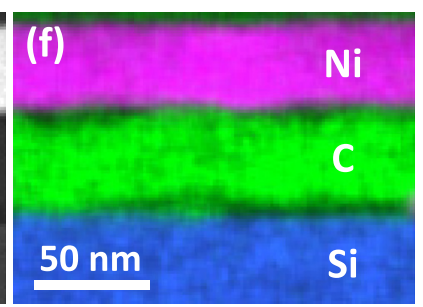

FIG. 2. Characterization of the samples. (a) Raman spectra obtained from the front and back sides of the sample before annealing. Raman spectra obtained from the (b) front and (c) back sides of the samples annealed at 600,800 , and $1000^{\circ} \mathrm{C}$ for $10 \mathrm{~min}$. (d) Raman spectra obtained from the front side of the samples without $\mathrm{Ni}$ annealed at 800,900 , and $1000^{\circ} \mathrm{C}$ for 10 min. Cross-sectional (e) HAADF-STEM image and (f) EDX elemental map of the sample annealed at $600^{\circ} \mathrm{C}$ for $10 \mathrm{~min}$. temperature $\left(>800^{\circ} \mathrm{C}\right) ;{ }^{19,24}$ however, much larger than that of MLG synthesized by metal-induced crystallization at low temperature $\left(<700^{\circ} \mathrm{C}\right) .{ }^{20,24,26}$ These results indicate that the resulting MLG layers contain relatively few defects compared with those obtained by conventional methods for lowtemperature synthesis.

Figure 2(d) shows that the annealing without Ni divides an a-C peak into broad $\mathrm{G}$ and $\mathrm{D}$ peaks because it shortens the average $\mathrm{C}-\mathrm{C}$ distance and leads to clustering of $\mathrm{sp}^{2}$ carbon in aromatic rings. ${ }^{10,23}$ The $\mathrm{G}$ and $\mathrm{D}$ peaks are quite broad, indicating that the $\mathrm{C}$ layer is almost amorphous even after $1000^{\circ} \mathrm{C}$ annealing. This means that the Ni catalyst has lowered the crystallization temperature of a-C by more than $400^{\circ} \mathrm{C}$. The difference of the crystallization temperatures of a-C between with and without $\mathrm{Ni}$ is large compared with the case of the MILE for Si and Ge. ${ }^{31,32}$ Considering the mechanism of MILE, the upper thickness limit of the MLG is determined by the relationship between the diffusion rate of $\mathrm{C}$ atoms into $\mathrm{Ni}$ and spontaneous nucleation rate in a-C. Because $0.5-\mu \mathrm{m}$-thick $\mathrm{Si}$ layers form in the $\mathrm{Si}-\mathrm{Al}$ system, ${ }^{26}$ the C-Ni system will enable the synthesis of MLG layers much thicker than $1 \mu \mathrm{m}$. The synthesis temperature for layer exchange is determined by the solubility limit of amorphous materials in metals. ${ }^{32,33}$ The phase diagram of the C-Ni system suggests that the lower limitation of the synthesis temperature is approximately $500^{\circ} \mathrm{C}$, which will be achieved by increasing the annealing time. For further lowering of the synthesis temperature, changing the kind of the catalytic metal or preparing a proper interlayer between $\mathrm{C}$ and $\mathrm{Ni}$ is effective. $^{33,34}$

To ensure a layer exchange, the cross-sectional composition was measured using an analytical transmission electron microscope (TEM), FEI Tecnai Osiris operated at $200 \mathrm{kV}$, equipped with an energy dispersive X-ray spectrometer (EDX) and a high-angle annular dark-field scanning transmission electron microscopy (HAADF-STEM) system with a probe diameter of $\sim 1 \mathrm{~nm}$. The cross-sectional TEM samples were prepared by the conventional focused ion beam method. Figures 2(e) and 2(f) indicate that a Ni layer is clearly stacked on a $\mathrm{C}$ layer on the $\mathrm{SiO}_{2}$ substrate. Thus, we directly formed MLG on the substrate by layer exchange between a-C and $\mathrm{Ni}$ layers at a temperature as low as $600^{\circ} \mathrm{C}$.

The detailed cross-sectional structure of the sample grown at $600^{\circ} \mathrm{C}$ was investigated using the TEM. Figure 3(a) shows that the MLG layer ripples between the Ni layer and the substrate. As shown in Fig. 3(b), the dark-field TEM image using the $\mathrm{C}\{002\}$ plane reflection showed a bright contrast of the MLG layer in the entire region ( $6 \mu \mathrm{m}$ width) processed for the TEM observation. This result indicates that the MLG layer is highly $\{002\}$ oriented. In MILE, energetically stable planes appear to minimize the free energy of the systems. ${ }^{28,32}$ The $\{002\}$ oriented growth of the MLG is likely because the $\{002\}$ plane has the lowest surface energy in graphite. ${ }^{38}$ This behavior is consistent with the other studies on the metal-induced synthesis of graphene: $\{002\}$ oriented graphene precipitate from metals. ${ }^{7-13}$ The selected-area electron diffraction (SAED) pattern in Fig. 3(c) shows slightly arced spots besides the spots corresponding to $\mathrm{Ni}$. The lattice spacing calculated from the arced spots of $0.343 \mathrm{~nm}$ is in close agreement with $\mathrm{C}\{002\}$ in graphite. Although it was difficult 


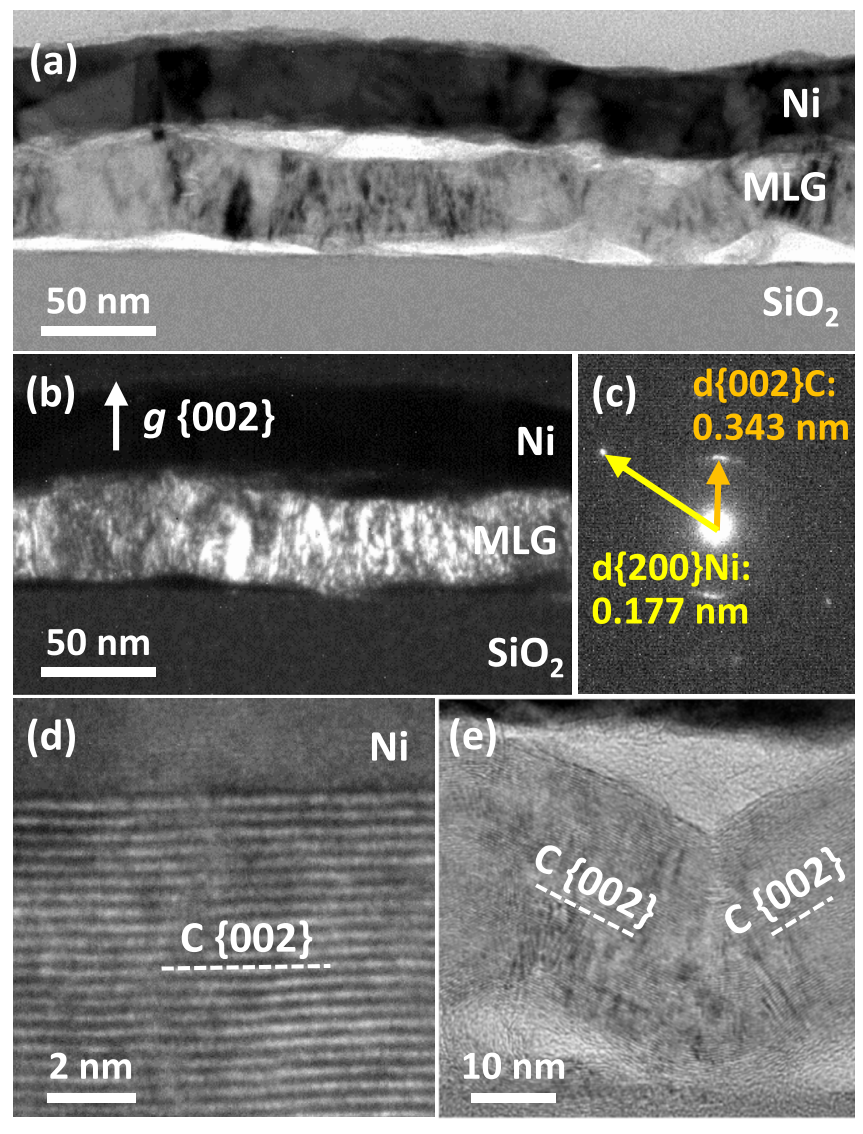

FIG. 3. Characterization of the cross section of the sample annealed at $600^{\circ} \mathrm{C}$ for $10 \mathrm{~min}$. (a) Bright-field TEM image. (b) Dark-field TEM image using the $\mathrm{C}\{002\}$ plane reflection. (c) SAED pattern taken from the region including the Ni and MLG layers with a selected area of $200 \mathrm{~nm}$ diameter. High-resolution lattice images of the MLG layer showing (d) a Ni-contacted region and (e) a rippling region.

to directly observe grain boundaries in the MLG layer in both plane and cross-sectional TEM images, the SAED analyses indicated that the grain size was approximately several hundred nm.

Figure 3(d) shows that the MLG layer in contact with the Ni layer is completely $\{002\}$ oriented. Meanwhile, Fig. $3(\mathrm{e})$ shows that the $\{002\}$ planes are in line with the rippling MLG layer. This accounts for columnar contrasts in the dark-field TEM image in Fig. 3(b) and slightly arced spots in the SAED pattern in Fig. 3(c). Figure 3(e) indicates that there is "something" but not a void in the spaces between the rippling MLG and the Ni layer or substrate. The EDX measurement showed carbon signals from the something; however, the signals are weaker than those from the $\{002\}$ oriented MLG layer. This behavior is likely attributed to the difference of the density of $\mathrm{C}$ atoms in the current direction of observation. The dark field TEM image in Fig. 3(b) indicates that the something is not $\{002\}$ oriented. The something is therefore considered to be randomly oriented grains of MLG. The origin of the rippling is not completely understood, but it possibly relates to the formation of randomly oriented grains that may interfere with the straight lateral growth of the MLG layer.

After removing the Ni layers, we found that the MLG layers remained on the substrates for all of the samples by the naked eye, as representatively shown in the insertion in
Fig. 4(c). We evaluated the surface structure of the samples using scanning electron microscopy (SEM, JEOL JSM$7001 \mathrm{~F})$ operated at $25 \mathrm{kV}$, equipped with EDX. Figures 4(a)-4(c) show that the lower annealing temperature $\left(600^{\circ} \mathrm{C}\right)$ gives a more uniform MLG layer. Figure 4(a) shows a nonuniform contrast originating from the uneven MLG layer. Because the configuration of the semiconductor layer grown by MILE reflects that of the metal layer, ${ }^{27,32}$ the morphology of the MLG layer grown at $1000^{\circ} \mathrm{C}$ likely arises from deformation of the Ni layer during annealing. As shown in Figs. 4(b) and 4(c), the MLG layers formed at 600 and $800{ }^{\circ} \mathrm{C}$ contain holes and hills. These morphologies are almost the same as those of the semiconductor layers grown by MILE. ${ }^{27,32}$ Nevertheless, the MLG obtained at $600^{\circ} \mathrm{C}$ shows the highest level of uniformity among MLG directly formed on insulators using metal-induced solid-phase crystallization at low temperature $\left(<800^{\circ} \mathrm{C}\right){ }^{20,24}$ Figure $4(\mathrm{~d})$ shows the peaks corresponding to $\mathrm{C}, \mathrm{Si}$, and $\mathrm{O}$. These elements originate from the MLG layer and the $\mathrm{SiO}_{2}$ substrate because the detection depth is
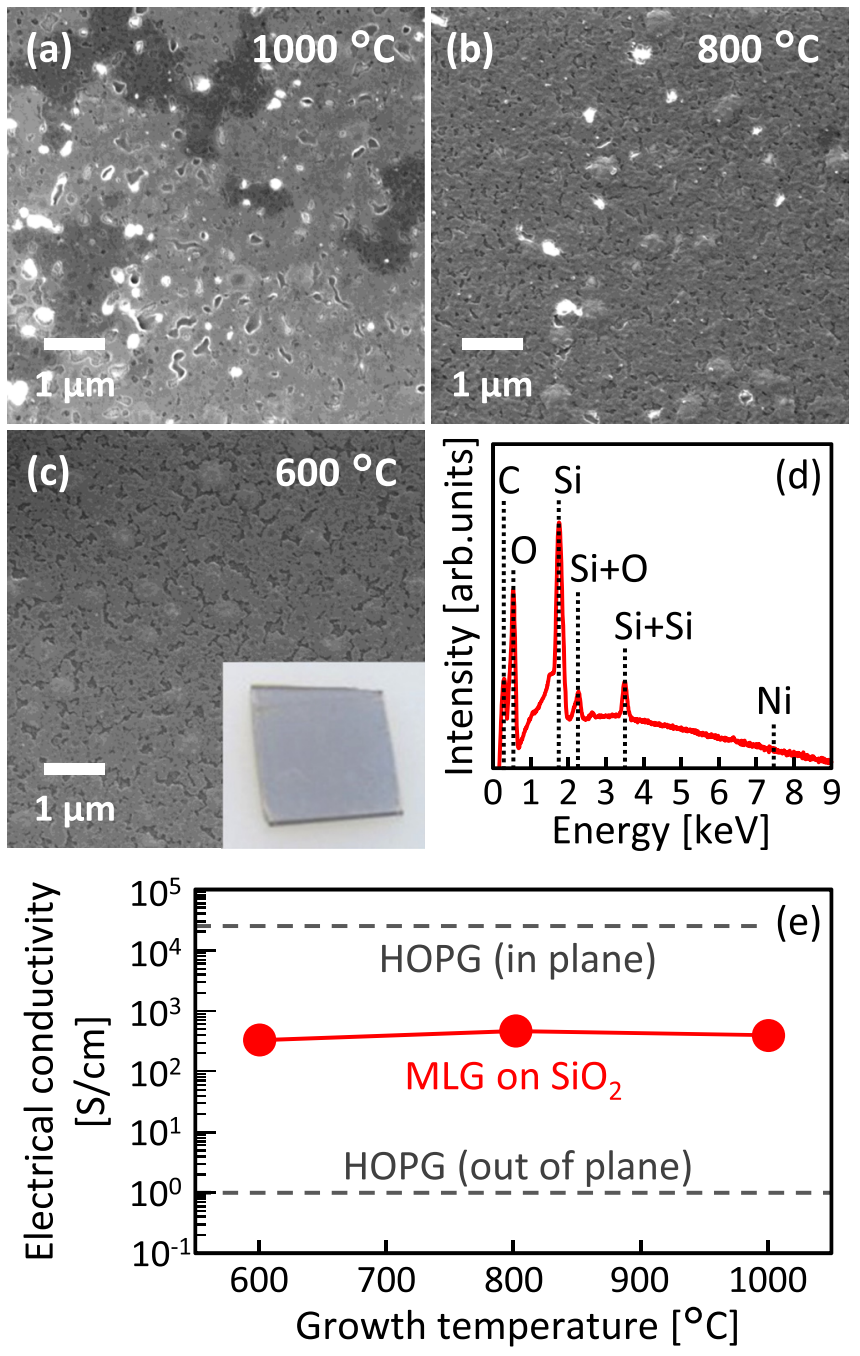

FIG. 4. Characterization of the annealed samples after removing Ni. SEM images of the samples annealed at (a) 1000 , (b) 800 , and (c) $600{ }^{\circ} \mathrm{C}$ for $10 \mathrm{~min}$. The insertion in (c) shows the optical micrograph of the $600{ }^{\circ} \mathrm{C}$ annealed sample (size: $\sim 5 \times 5 \mathrm{~mm}^{2}$ ). (d) EDX spectrum of sample annealed at $600{ }^{\circ} \mathrm{C}$. (e) Electrical conductivities of the MLG layers as a function of growth temperature. For comparison, the data from HOPG along in-plane and out-of-plane directions are shown by dotted lines. 
more than $1 \mu \mathrm{m}$ in the EDX measurement. We note that the Ni concentration in the MLG layer is below the detection limit of $\operatorname{EDX}(\sim 1 \%)$. Such low metal contamination in the resulting layer is a typical feature of MILE, which is limited by the solubility. ${ }^{32,33}$

The electrical conductivities of the MLG layers were measured by the van der Pauw method. Figure 4(e) shows that the electrical conductivities are approximately $400 \mathrm{~S}$ $\mathrm{cm}^{-1}$ in the whole range of growth temperature. This value is higher than the electrical conductivity of highly oriented pyrolytic graphite (HOPG, grain size: $\sim 5 \mu \mathrm{m}$ ) along the outof-plane direction, ${ }^{23}$ reflecting the high orientation of the MLG. The electrical conductivity of the MLG is, however, lower than that of the HOPG along the in-plane direction, mainly because the grain size of the MLG is one order of magnitude smaller than that of the HOPG. Because MILE has many growth parameters to enlarge the grain size of the resulting layer, there is a great potential for the lowtemperature synthesis of MLG with high electrical and thermal conductivities on insulators.

In conclusion, we directly synthesized MLG on an insulating substrate using MILE growth of a-C with a Ni catalyst. Raman measurements indicate that the MLG formed at $600{ }^{\circ} \mathrm{C}$ has a higher crystal quality than MLG formed by conventional techniques. The MLG layer ripples between the $\mathrm{Ni}$ layer and the substrate but contains no obvious defects. Thus, we have demonstrated that the MILE technique, which was developed for semiconductors on insulators, is also useful for carbon materials on insulators. Further investigation will enhance the quality of MLG and open the possibility for its incorporation into advanced electronic devices.

This work was financially supported by the Nanotech CUPAL. Some experiments were performed at the International Center for Young Scientists and the Molecule and Material Synthesis Platform in NIMS.

${ }^{1}$ S. Biswas and L. T. Drzal, ACS Appl. Mater. Interfaces 2, 2293 (2010).

${ }^{2}$ A. A. Balandin, Nat. Mater. 10, 569 (2011).

${ }^{3}$ R. Murali, Y. Yang, K. Brenner, T. Beck, and J. D. Meindl, Appl. Phys. Lett. 94, 243114 (2009).

${ }^{4}$ C. A. Klein, Rev. Mod. Phys. 34, 56 (1962).

${ }^{5}$ Q. Yu, L. A. Jauregui, W. Wu, R. Colby, J. Tian, Z. Su, H. Cao, Z. Liu, D. Pandey, D. Wei, T. F. Chung, P. Peng, N. P. Guisinger, E. A. Stach, J. Bao, S.-S. Pei, and Y. P. Chen, Nat. Mater. 10, 443 (2011).

${ }^{6}$ K. S. Novoselov, A. K. Geim, S. V. Morozov, D. Jiang, Y. Zhang, S. V. Dubonos, I. V. Grigorieva, and A. A. Firsov, Science 306, 666 (2004).

${ }^{7}$ C.-Y. Su, A.-Y. Lu, C.-Y. Wu, Y.-T. Li, K.-K. Liu, W. Zhang, S.-Y. Lin, Z.-Y. Juang, Y.-L. Zhong, F.-R. Chen, and L.-J. Li, Nano Lett. 11, 3612 (2011).

${ }^{8}$ T. Kato and R. Hatakeyama, ACS Nano 6, 8508 (2012).
${ }^{9}$ W.-C. Yen, Y.-Z. Chen, C.-H. Yeh, J.-H. He, P.-W. Chiu, and Y.-L. Chueh, Sci. Rep. 4, 4739 (2014).

${ }^{10}$ K. Murakami, S. Tanaka, A. Hirukawa, T. Hiyama, T. Kuwajima, E. Kano, M. Takeguchi, and J. Fujita, Appl. Phys. Lett. 106, 093112 (2015).

${ }^{11}$ K. Ueno, H. Ichikawa, and T. Uchida, Jpn. J. Appl. Phys., Part 1 55, 04EC13 (2016).

${ }^{12}$ H. Liu, S. Zhu, and W. Jiang, J. Mater. Sci. Mater. Electron. 27, 2795 (2016).

${ }^{13}$ H. J. Park, B. W. Ahn, T. Y. Kim, J. W. Lee, Y. H. Jung, Y. S. Choi, Y. Il Song, and S. J. Suh, Thin Solid Films 587, 8 (2015).

${ }^{14}$ Z. Peng, Z. Yan, Z. Sun, and J. M. Tour, ACS Nano 5, 8241 (2011).

${ }^{15}$ R. Hirano, K. Matsubara, G. Kalita, Ya. Hayashi, and M. Tanemura, Nanoscale 4, 7791 (2012).

${ }^{16}$ J. Kwak, J. H. Chu, J.-K. Choi, S.-D. Park, H. Go, S. Y. Kim, K. Park, S.D. Kim, Y.-W. Kim, E. Yoon, S. Kodambaka, and S.-Y. Kwon, Nat. Commun. 3, 645 (2012).

${ }^{17}$ K. Banno, M. Mizuno, K. Fujita, T. Kubo, M. Miyoshi, T. Egawa, and T. Soga, Appl. Phys. Lett. 103, 082112 (2013).

${ }^{18}$ W. Xiong, Y. S. Zhou, W. J. Hou, T. Guillemet, J. F. Silvain, Y. Gao, M. Lahaye, E. Lebraud, S. Xu, X. W. Wang, D. A. Cullen, K. L. More, L. Jiang, and Y. F. Lu, RSC Adv. 5, 99037 (2015).

${ }^{19}$ S. J. Byun, H. Lim, G. Y. Shin, T. H. Han, S. H. Oh, J. H. Ahn, H. C. Choi, and T. W. Lee, J. Phys. Chem. Lett. 2, 493 (2011).

${ }^{20} \mathrm{~K}$. Gumi, Y. Ohno, K. Maehashi, K. Inoue, and K. Matsumoto, Jpn. J. Appl. Phys., Part 1 51, 06FD12 (2012).

${ }^{21}$ M. Tamaoki, H. Imaeda, S. Kishimoto, and T. Mizutani, Appl. Phys. Lett. 103, 183114 (2013).

${ }^{22}$ H. Tanaka, S. Obata, and K. Saiki, Carbon 59, 472 (2013).

${ }^{23}$ M. Sato, M. Inukai, E. Ikenaga, T. Muro, S. Ogawa, Y. Takakuwa, H. Nakano, A. Kawabata, M. Nihei, and N. Yokoyama, Jpn. J. Appl. Phys., Part 151, 04DB01 (2012).

${ }^{24}$ M. Sato, M. Takahashi, H. Nakano, Y. Takakuwa, M. Nihei, S. Sato, and N. Yokoyama, Jpn. J. Appl. Phys., Part 1 53, 04EB05 (2014).

${ }^{25}$ M. Kosaka, S. Takano, K. Hasegawa, and S. Noda, Carbon 82, 254 (2015).

${ }^{26}$ Q. Q. Zhuo, Q. Wang, Y. P. Zhang, D. Zhang, Q. L. Li, C. H. Gao, Y. Q. Sun, L. Ding, Q. J. Sun, S. D. Wang, J. Zhong, X. H. Sun, and S. T. Lee, ACS Nano 9, 594 (2015).

${ }^{27}$ O. Nast, T. Puzzer, L. M. Koschier, A. B. Sproul, and S. R. Wenham, Appl. Phys. Lett. 73, 3214 (1998).

${ }^{28}$ M. Kurosawa, N. Kawabata, T. Sadoh, and M. Miyao, Appl. Phys. Lett. 95, 132103 (2009).

${ }^{29}$ Z. Wang, L. Gu, L. P. H. Jeurgens, F. Phillipp, and E. J. Mittemeijer, Nano Lett. 12, 6126 (2012).

${ }^{30}$ R. Numata, K. Toko, N. Saitoh, N. Yoshizawa, N. Usami, and T. Suemasu, Cryst. Growth Des. 13, 1767 (2013).

${ }^{31}$ K. Toko, R. Numata, N. Saitoh, N. Yoshizawa, N. Usami, and T. Suemasu, J. Appl. Phys. 115, 094301 (2014).

${ }^{32}$ K. Toko, M. Kurosawa, N. Saitoh, N. Yoshizawa, N. Usami, M. Miyao, and T. Suemasu, Appl. Phys. Lett. 101, 072106 (2012).

${ }^{33}$ J.-H. Park, K. Kasahara, K. Hamaya, M. Miyao, and T. Sadoh, Appl. Phys. Lett. 104, 252110 (2014).

${ }^{34}$ K. Toko, R. Numata, N. Oya, N. Fukata, N. Usami, and T. Suemasu, Appl. Phys. Lett. 104, 022106 (2014).

${ }^{35}$ H. Higashi, K. Kasahara, K. Kudo, H. Okamoto, K. Moto, J.-H. Park, S. Yamada, T. Kanashima, M. Miyao, I. Tsunoda, and K. Hamaya, Appl. Phys. Lett. 106, 041902 (2015).

${ }^{36}$ M. Nakata, K. Toko, N. Saitoh, N. Yoshizawa, and T. Suemasu, Scr. Mater. 122, 86 (2016).

${ }^{37}$ T. Sadoh, J. Park, R. Aoki, and M. Miyao, Jpn. J. Appl. Phys., Part 1 55, 03CB01 (2016).

${ }^{38}$ S. K. Rhee, J. Am. Ceram. Soc. 55, 300 (1972). 